\title{
Genomic insights into the metabolic flexibility of the acid-tolerant Fe(II)- oxidizer Sideroxydans sp. CL21
}

\author{
REBECCA E. COOPER ${ }^{1 *}$, JESSICA FINCK ${ }^{1}$, RENE \\ HOOVER $^{2}$, Clara S. CHAN ${ }^{2,3}$, KIRSTEN KÜSEL ${ }^{1}$
}

${ }^{1}$ Institute of Biodiversity, Friedrich Schiller University Jena,

Germany (*correspondence:rebecca.cooper@uni-jena.de)

${ }^{2}$ Department of Earth Sciences, University of Delaware, Newark, Delaware, USA

${ }^{3}$ School of Marine Science and Policy, University of

Delaware, Newark, Delaware, USA

Chemolithotrophic, microaerophilic, $\mathrm{Fe}(\mathrm{II})$-oxidizing bacteria (FeOB), including Sideroxydans sp., found within the family Gallionellaceae are known to oxidize $\mathrm{Fe}(\mathrm{II})$ and to fix $\mathrm{CO}_{2}$ via the RubisCO pathway. To elucidate the metabolic potential of Sideroxydans sp. CL21, a gram-negative FeOB isolated from the slightly acidic, minerotrophic Schlöppnerbrunnen fen, we used the PacBio RS II platform to sequence and analyze the genome. The genome has a single chromosome of $3.77 \mathrm{Mb}$ encoding 3795 genes [1]. Genome-resolved characterization of Sideroxydans sp. CL21 revealed genes encoding homologs of the $\mathrm{Fe}(\mathrm{II})$ oxidation genes $m t o A B$ and $c y c 2$. We also identified genes encoding an acetate permease and transporter, as well as a lactate permease and dehydrogenase, suggesting strain CL21 can also use organic carbon, thus revealing an atypical mixotrophic metabolism. In addition, the genome contains multiple gene clusters encoding NiFe hydrogenases, homologs of the sulfur oxidation (sox) genes, and genes involved in sulfate uptake and assimilation. These findings suggest strain CL21 is capable of using $\mathrm{H}_{2}$ or sulfur compounds as an alternative electron donor. To validate the metabolic versatility of Sideroxydans sp. CL21, we used increasing concentrations of $\mathrm{H}_{2}(0-5 \%)$ and $\mathrm{S}_{2} \mathrm{O}_{3}{ }^{2-}(0-5 \mathrm{mM})$, with or without $\mathrm{FeS}$, to determine growth and electron donor consumption rates under autotrophic or mixotrophic conditions $(0-5 \mathrm{mM}$ lactate or acetate). Incubations amended with $1 \mathrm{mM}$ lactate, $5 \mathrm{mM} \mathrm{S}_{2} \mathrm{O}_{3}{ }^{2}$, and FeS resulted in higher 16S rRNA gene copies over $17 \mathrm{~d}$, compared to incubations with $\mathrm{FeS}$ and $1 \mathrm{mM}$ lactate or $1 \mathrm{mM}$ acetate. Interestingly, maximal16S rRNA gene copies were highest in incubations amended with both $\mathrm{H}_{2}$ and FeS plus an organic carbon source. 16S rRNA gene copies in incubations with organic carbon and either $\mathrm{H}_{2}$ or $\mathrm{FeS}$ were similar to each other, albeit slightly lower than in incubations with both donors. Additionally, the rate of $\mathrm{H}_{2}$ consumption was faster in the absence of $\mathrm{Fe}(\mathrm{II})$, suggesting $\mathrm{H}_{2}$ may be the preferred electron donor when organic carbon is present. Taken together, our combined genome-resolved and ongoing experimental results will help to better assess the impact of Sideroxydans sp. CL21-mediated $\mathrm{Fe}$ (II) oxidation on the biogeochemical iron cycle in environments where inorganic and organic carbon sources, as well as alternative electron donors, are abundant.

[1] Cooper, et al. (2020) MRA, 9:e01444-19. 